\title{
Scalar Properties in the Overfire Region of Sooting Turbulent Diffusion Flames
}

\author{
Y. R. SIVATHANU, J. P. GORE and G. M. FAETH \\ Department of Aerospace Engineering, The University of Michigan, Ann Arbor, MI 48109-2140
}

\begin{abstract}
The scalar structure of the overfire (fuel-lean) region of sooting turbulent diffusion flames was investigated, considering ethylene and acetylene burning in air. Measurements and predictions are reported of the mean concentrations of major gas species and mean soot volume fractions. Predictions were based on the conserved-scalar formalism in conjunction with the laminar flamelet approximation. The comparison between predictions and measurements was encouraging, suggesting that state relationships for major gas species, found in laminar diffusion flames, were preserved in the overfire region of the turbulent flames. Measurements also indicated nearly constant soot generation efficiencies from point to point in the overfire region for sufficiently long characteristic residence times to yield nearly universal soot volume fraction state relationships at the same conditions. However, effects attributed to finite-rate chemistry were observed at shorter characteristic residence times, causing spatial variations of soot generation efficiencies in the overfire region, with associated loss of universal soot volume fraction state relationships.
\end{abstract}

\section{NOMENCLATURE}

a acceleration of gravity

$d$ burner exit diameter

$f$ mixture fraction

$f_{v} \quad$ soot-volume fraction

$i \quad(-1)^{\frac{1}{2}}$

$k \quad$ turbulence kinetic energy

$m$ complex index of refraction of soot

$\dot{m}_{o}$ burner mass flow rate

$Q_{R}$ radiative heat-loss fraction

$r$ radial distance

$R e$ burner Reynolds number

$R i$ burner Richardson number

$u \quad$ streamwise velocity

$x \quad$ height above burner exit

\section{Greek}

$\nu \quad$ kinematic viscosity

$\rho$ density

\section{Subscripts}

$o$ burner exit condition

\section{Superscripts}

$\left(^{-}\right)$time-averaged quantity

( ) Favre-averaged quantity

\section{INTRODUCTION}

Radiant energy transport influences the burning rate, the rate of spread, and the structure of fires within structures-particularly for soot-containing luminous flames. In order to better understand these phenomena, studies of the structure and radiation properties of luminous turbulent ethylene/air and acetylene/air diffusion flames were recently completed in this laboratory $[1,2]$. These studies emphasized radiation properties, however, leaving uncertainties concerning scalar structure, particularly in the overfire (lean) region. The objective of the present investigation was to consider the scalar structure of the overfire region of the same flames, with particular emphasis on the scalar properties needed for analysis of flame radiation.

Predictions of flame radiation require informa-

Copyright $(\mathcal{C} 1988$ by The Combustion Institute Published by Elsevier Science Publishing Co., Inc. 52 Vanderbilt Avenue, New York, NY 10017 
tion concerning the concentrations of major gas species and the properties of soot $[1,2]$. Soot particles in flames generally have diameters smaller than $100 \mathrm{~nm}$, while infrared radiation having wavelengths greater than $1000 \mathrm{~nm}$ is most important; therefore, the Rayleigh limit of small particles is generally acceptable for estimating the spectral absorption coefficients of soot, and scattering can be ignored [3]. As a result, the only soot properties needed for radiation analysis are the refractive indices and volume fractions of soot. There is some controversy concerning the refractive indices of soot; however, they are relatively independent of the original fuel and estimates are available in the literature [3]. Thus, soot volume fractions are the soot property that must be found from predictions of flame structure, in order to analyze radiation from luminous flames.

The laminar flamelet concept for diffusion flames, proposed by Bilger [4] and Liew et al. [5, 6], has significant potential for simplifying estimation of scalar properties needed for radiation analysis of turbulent diffusion flames [1, 2]. The concept is based on the observation that the concentrations of major gas species are nearly universal functions of mixture fraction (the fraction of mass which originated from the burner) within laminar flames, relatively independent of position and the degree of local flame stretch [4]. The concept is applied to turbulent flames by assuming that they correspond to wrinkled laminar flames having the same universal correlations between scalar properties and mixture fraction. The latter can be found by analysis of turbulent mixing; therefore, the laminar flamelet concept replaces the problem of complex flame chemistry in a turbulent environment by routine measurements in laminar flames.

Correlations between scalar properties and mixture fraction have come to be called "state relationships" [7]. State relationships for the

\footnotetext{
${ }^{1}$ Exceptions to these correlations are observed in regions of high flame stretch, associated with points of flame attachment and extinction $[5,6]$; however, such regions are generally only a small fraction of the entire flow field. Minor gas species, like radicals and pollutants, exhibit larger regions where universality is lost [7]; however, except for soot, these substances generally have little effect on flame radiation.
}

concentration of major gas species have been measured for a variety of fuels burning in air at normal temperatures and pressures, as follows: hydrogen $[4,8]$, carbon monoxide [9], methane $[4,10]$, propane [11], n-heptane [4], ethylene [1], and acetylene [2]. Local thermodynamic equilibrium is generally observed for lean conditions; however, hydrocarbon fuels depart significantly from equilibrium at fuel-rich conditions due to slow chemical processes associated with fuel decomposition and soot formation. Nevertheless, a quasi-equilibrium is reached at fuel-rich conditions for these materials as well, yielding universal correlations of major gas species concentrations as a function of mixture fraction, as required by the laminar flamelet concept [4-6].

If the laminar flamelet concept can be extended to soot volume fractions, it would vastly simplify estimation of scalar properties needed for radiation analysis of luminous flames. Existing measurements by Kent and Bastin [12], Kent [13], and Becker and Liang [14] for turbulent soot-containing flames provide some evidence that this potential may exist for a useful range of flame conditions-particularly for the buoyant turbulent flames typical of unwanted fires. Kent and Bastin [12] used laser extinction measurements to study effects of residence time on soot concentrations within acetylene/air diffusion flames. They observed that soot concentrations become relatively independent of residence time, for sufficiently long residence times, suggesting that a quasiequilibrium condition was being approached for soot properties. Subsequently, Kent [13] determined that characteristic soot volume fractions (a parameter related to the maximum soot volume fractions in a turbulent flame) were relatively independent of residence time for sufficiently long residence times and were related to the same parameter found in laminar flames for a variety of fuels. Becker and Liang [14] studied turbulent sooting flames for a wide range of conditions. They found that the mass percentage of fuel carbon that was converted to soot and emitted from the flames, defined as the soot generation efficiency [15], also became relatively independent of flame conditions for sufficiently long residence times. All these observations suggest a potential for universal soot volume state relation- 
ships, particularly at sufficiently long residence times.

Soot volume fraction state relationships were examined during earlier studies of ethylene and acetylene flames in this laboratory [1, 2]. Measurements in laminar jet flames showed that soot volume fractions were only appreciable for a relatively narrow range of mixture fractions in the fuel-rich region (soot spikes) near the stoichiometric condition. State relationships for soot volume fractions were found within the soot spikes; however, the correlations were inferior to the state relationships for major gas species. This was attributed to effects of finite-rate chemistry, laminar hydrodynamics associated with the small diffusivities of soot particles, and effects of thermophoresis of soot particles $[16,17]$. Nevertheless, subsequent use of these soot volume fraction state relationships for predictions of radiation emission and absorption in turbulent flames yielded encouraging agreement with measurements, suggesting that they were at least sufficiently universal to be useful for analyzing flame radiation properties $[1,2]$. The situation is helped by the relative insensitivity of continuum-radiation predictions to estimates of soot volume fractions in comparison to other properties; for example, sensitivity studies showed that a $5 \%$ increase in soot volume fractions increased spectral intensities in the continuum less than $3 \%$, while a similar increase in temperature yielded intensity increases of $30-50 \%$ [2].

The earlier studies of turbulent ethylene and acetylene flames $[1,2]$ highlighted the importance of the presence of soot in the overfire region. In particular, the turbulent flames emitted soot, and emission and extinction of radiation by soot in the overfire region was significant. In order to treat effects of soot on the radiation properties of the overfire region, the soot volume fraction state relationships were extended into the lean region. This was done by selecting constant volumetric soot generation coefficients ${ }^{2}$ for each fuel. This is equivalent to assuming that the soot volume

\footnotetext{
${ }^{2}$ The volumetric soot generation coefficient is defined as the volume of soot emitted from the flame per unit mass of fuel reacted.
}

fraction and the mixture fraction when soot oxidation ceases (near stoichiometric conditions) are the same for all paths through the flame, and that subsequently soot only passively mixes in the overfire region. The selections of volumetric soot generation efficiencies were optimized to some extent by extinction measurements in the overfire region. This approach yielded encouraging radiation predictions for the turbulent flames $[1,2]$; however, a more direct evaluation of the lean portions of the soot volume fraction state relationships would be desirable. Finally, additional assessment of scalar structure predictions is needed in order to evaluate effects of errors in the structure analysis on the radiation predictions [1, 2].

The present investigation sought to supply information on soot volume fractions and scalar structure in the overfire region of the turbulent ethylene and acetylene flames studied earlier [1, 2]. Measurements were made of the mean concentrations of major gas species and soot volume fractions. Predictions of these properties, using methods developed earlier [1, 2], were evaluated using the new measurements. Soot volume fraction state relationships for the overfire region and soot generation efficiencies were also studied by directly correlating measured soot volume fractions and mixture fractions.

The paper begins with a brief description of experimental and theoretical methods. This is followed by discussion of the findings for the turbulent acetylene and ethylene flames, considering predicted and measured mixture fractions, species concentrations, soot volume fractions, and the correlation of soot volume fraction state relationships in the overfire region. The paper concludes with discussion of soot generation efficiencies for the present flames and their comparison with the measurements of others.

\section{EXPERIMENTAL METHODS}

\section{Apparatus}

The test arrangement was the same as the earlier studies of turbulent ethylene and acetylene flames $[1,2]$. The fuels were injected vertically upward from a water-cooled burner having an exit diame- 
TABLE 1

Summary of Test Conditions ${ }^{\mathrm{a}}$

\begin{tabular}{|c|c|c|c|c|}
\hline \multirow{2}{*}{ Reynolds number $^{b}$} & \multicolumn{2}{|c|}{ Ethylene } & \multicolumn{2}{|c|}{ Acetylene } \\
\hline & 6,370 & 12,740 & 5,300 & 9,200 \\
\hline Richardson number ${ }^{c} \times 10^{4}$ & 1.8 & 0.38 & 4.5 & 1.4 \\
\hline$u_{o}(\mathrm{~m} / \mathrm{s})$ estimated $^{d}$ & 17.0 & 33.9 & 10.5 & 18.1 \\
\hline$u_{o}(\mathrm{~m} / \mathrm{s})$ measured & 16.7 & 36.1 & 11.8 & 20.6 \\
\hline$k_{o} \overline{2} / u_{0}$ & 0.050 & 0.048 & 0.13 & 0.13 \\
\hline Heat release rate $(\mathrm{kW})$ & 13.5 & 27.0 & 10.5 & 18.1 \\
\hline Radiative heat loss fraction (\%) & 36.0 & 34.4 & 57.0 & 59.0 \\
\hline Fuel flow rate $(\mathrm{mg} / \mathrm{s})$ & 310 & 620 & 217 & 376 \\
\hline Hydrogen flow rate $(\mathrm{mg} / \mathrm{s})$ & 1.9 & 9.6 & 1.9 & 1.9 \\
\hline
\end{tabular}

a Flow directed vertically upward from a 5-mm diameter passage in still air at normal temperature and pressure. Commercial grade ethylene (Linde Division of Union Carbide) and acetylene (Detroit Welding Supply) were used.

${ }^{b} \operatorname{Re}=u_{o} d / v$ based on fuel-gas properties at burner exit.

${ }^{c} R i=a d / u_{o}^{2}$.

${ }^{d} u_{o}=4 \dot{m}_{o} /\left(\pi d^{2} \rho\right)$ based on fuel-gas density at burner exit.

ter of $5 \mathrm{~mm}$. The flames were burned within a screened enclosure in order to reduce effects of room disturbances. The flames were attached at the burner exit by using a small flow of hydrogen, which was introduced through a slot just below the burner exit.

\section{Test Conditions}

Table 1 is a summary of the test conditions. Two flames each were considered for ethylene and acetylene. The test conditions were identical to [1, 2]; therefore, it was not necessary to repeat measurements of initial conditions and the velocity field, which are needed to initiate calculations and to verify flow predictions.

All flows had relatively high initial Reynolds numbers and were turbulent at the burner exit. Initial Richardson numbers were relatively low; however, effects of buoyancy were important for much of the flow because the surroundings were still. Thus, the radiative heat loss fractions of the flames are relatively independent of burner flow rate, which is characteristic of buoyant turbulent diffusion flames [18].

The present flames are similar to the longer residence time flames considered by Becker and
Liang [14]. They identified their measurements by Richardson ratios and characteristic residence times based on visible flame lengths. The present flames roughly correspond to Richardson ratios on the order of $10^{3}$, or characteristic residence times of 90-160 s (based on the definitions of these parameters of Becker and Liang [14]). Thus, the present flames are in the plateau region observed by Becker and Liang [14], where radiative heat loss fractions and soot generation efficiencies are nearly independent of the burner flow rate.

\section{Instrumentation}

Measurements were limited to mean concentrations of major gas species and laser extinction by soot to find soot volume fractions. Methods will be only briefly described because they were similar to past work $[1,2]$.

Sampling and analysis with a gas chromatograph were used to measure mean concentrations of major gas species. A water-cooled probe, having an inlet diameter of $6.3 \mathrm{~mm}$, was used for sampling. Sampling rates were crudely isokinetic, based on measured mean velocities along the axis and predictions of radial variations of velocity. This was adequate, however, as effects of dou- 
bling and halving sampling rates were small in comparison to experimental uncertainties. The construction of the probe and the sampling system, and the column arrangement and calibration of the gas chromatograph, were described by Gore [19]. Uncertainties in composition measurements $(95 \%$ confidence) are less than $15 \%$ for concentrations greater than $0.1 \%$ (by volume), rising to $50 \%$ at concentrations of $0.01 \%$ and becoming inversely proportional to concentration at lower concentrations. These uncertainties are largely governed by uncertainties in measuring gas chromatograph peak areas [19]. Mixture fractions were computed from these measurements, based on the measured concentrations of carbon and nitrogen and assuming that carbon:hydrogen ratios of the original fuel were preserved throughout the flow field. Uncertainties in these estimates (95\% confidence) range from $100 \%$ at $f-5 \times 10^{-4}$ to $30 \%$ at $f \sim 5 \times$ $10^{-2}$, and are roughly proportional to the mixture fraction in the intervening region. The uncertainties of the mixture fraction determinations are largely due to uncertainties of gas species concentrations and effects of fuel carbon in soot.

Laser extinction was measured using a heliumneon laser $(632.8 \mathrm{~nm})$, similar to the methods of earlier work [1, 2]. Two-wavelength measurements showed that soot particles in these flames approximated the small-particle Rayleigh scattering limit [2]. A chopper, operated at $800 \mathrm{~Hz}$, was used to control background and flame radiation and to improve signal-to-noise ratios. Uncertainties in mean extinction measurements (95\% confidence) are estimated to be less than $10 \%$, largely governed by finite sampling times [19].

Turbulent fluctuations have only a small effect on laser extinction measurements for these flames $[1,2]$. Therefore, the extinction measurements were deconvoluted to provide estimates of mean soot volume fractions, using the approach described by Santoro et al. [16]. In order to be consistent with earlier work $[1,2,16]$, soot volume fractions were computed using the soot refractive index measurements of Dalzell and Sarofim [20], i.e., $m=1.547-0.56 i$ at 632.8 $\mathrm{nm}$. Uncertainties in soot volume fraction measurements depend on the fuel and position in the flames. They were estimated by perturbing the deconvolution calculations by the uncertainties of the extinction measurements. The uncertainties ( $95 \%$ confidence) can be expressed in terms of the soot volume fractions for each fuel as follows: acetylene, $15 \%$ at $4 \mathrm{ppm}$ and $300 \%$ at $0.06 \mathrm{ppm}$; ethylene, $20 \%$ at $0.5 \mathrm{ppm}$ and $300 \%$ at 0.004 ppm. Uncertainties are roughly proportional to soot volume fractions in the intervening region. Potential errors in estimations of refractive indices and effects of Mie scattering introduce additional uncertainties, which will be discussed later.

\section{THEORETICAL METHODS}

Analysis of flame structure was similar to past work $[1,2,8-11]$ and will be only briefly described. Major assumptions of the structure analysis are as follows: low Mach number boundary-layer flow with no swirl; equal exchange coefficients of all species and heat; buoyancy affects only the mean flow; negligible changes of potential energy; and radiant heat loss from each element of the flow taken to be the same fraction of the chemical energy transformation of the element as the flame as a whole. All these assumptions are either justified by the present test conditions or by acceptable performance in the past $[1,2,8-11]$. The most questionable assumption involves ignoring radiant energy exchange within the acetylene flames. These flames lose a large fraction, ca. $60 \%$, of their energy release of reaction by radiation, suggesting significant coupling between structure and radiation properties. Nevertheless, the approximation was still adopted in order to avoid the complications of combined structure and radiation analysis for the present.

Flow properties were found using a Favreaveraged $k-\epsilon-g$ turbulence model proposed by Bilger [21], with specific modifications and empirical constants due to Jeng and Faeth [10]. The laminar flamelet approximation for diffusion flames was used to relate scalar properties to the mixture fraction, following Bilger [4]. State relationships for the concentrations of major gas species, soot volume fractions, temperature, and density were obtained from the earlier studies [1, 2].

Initial conditions for the structure calculations 
were developed by linear extrapolation of measurements of mean and fluctuating velocities at $x /$ $d=2$ [2]. Similarly, the specification of boundary conditions and the details of the numerical computations follow past practice $[1,2,19]$.

\section{RESULTS AND DISCUSSION}

\section{Acetylene/Air Flames}

\section{Species Concentrations}

Sampling measurements of gas species concentrations fall between time- and density-weighted (Favre)-averages; however, the degree of density weighting is generally unknown [7]. The differences between the two limiting averages, however, are less than $15 \%$ for present test conditions. Such differences are comparable to experimental uncertainties; therefore, only Favre-averaged predictions of mixture fractions and species concentrations are illustrated in the following, in order to reduce cluttering of the figures.

Figure 1 is an illustration of predicted and measured mean mixture fractions for the two turbulent acetylene/air flames. Results are plotted as a function of $r / x$ (the similarity variable most frequently used for turbulent jets and plumes) at various heights above the burner exit. The flame tips (based here and in the following on the location of the mean stoichiometric mixture ratio along the axis) are reached at $x / d \sim 75$ and 80 for the low and high Reynolds number flames.

The coordinates used in Fig. 1 provide a direct indication of flow widths and levels of mixing in the flames; therefore, plots of this type are sensitive indicators of the performance of turbulent mixing analysis. Both the agreement between predictions and measurements and the predicted trends with respect to burner Reynolds numbers are reasonably good. The largest discrepancies between predictions and measurements are at $x / d$ $=130$ for the lower Reynolds number flame, where measured mixture fractions are well below predictions. This behavior is probably due to ambient disturbances that deflect the flow, reducing apparent concentration levels of fuel-containing species; this effect is particularly difficult to

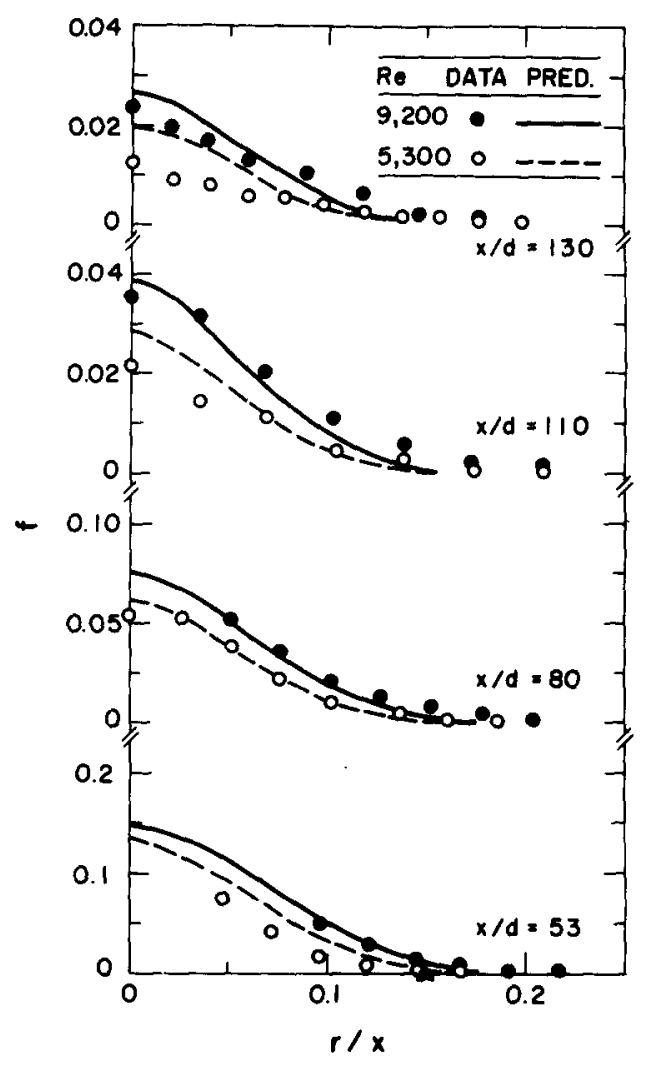

Fig. 1. Mixture fraction distributions for acetylene/air.

control in weak flows far from the burner. In general, the performance of the analysis is consistent with earlier findings along the axis of these flames [2] and is characteristic of earlier evaluations of similar predictions for a variety of other turbulent diffusion flames [1, 8-11].

Typical predictions and measurements of the concentrations of major gas species $\left(\mathrm{N}_{2}, \mathrm{O}_{2}\right.$, $\mathrm{C}_{2} \mathrm{H}_{2}, \mathrm{CO}, \mathrm{CO}_{2}$ ) are illustrated in Figs. 2 and 3. Mean species mole fractions are plotted as a function of $r / x$ for $x / d=53$ and 110 . The results suggest no particular difficulty with the laminar flamelet concept for gas species in these heavily sooting flames. The comparison between predictions and measurements is similar to that in sootfree flames, where local thermodynamic equilibrium is essentially maintained [8, 9]. Areas of discrepancies between predictions and measurements generally are associated with regions where errors are present in the mixture fraction predic- 


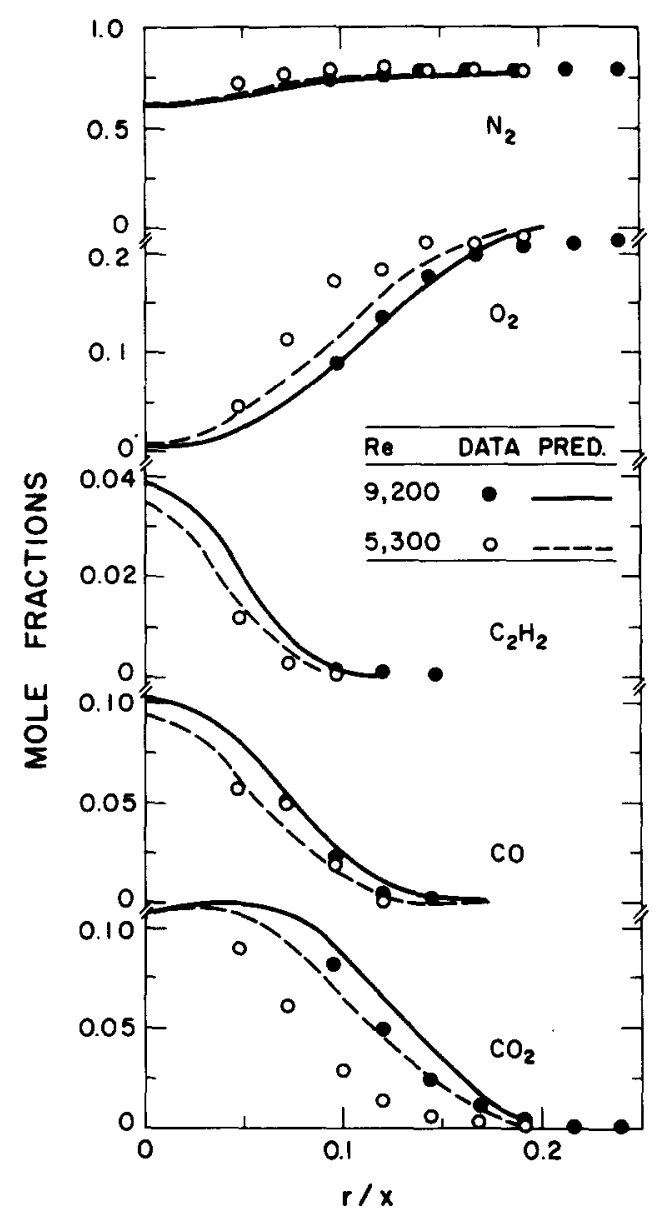

Fig. 2. Gas species concentrations (acetylene/air, $x / d=53$ ).

tions as illustrated in Fig. 1. It should be noted, however, that present measurements emphasize the overfire (lean) region of the flames, where local thermodynamic equilibrium is also a reasonably good approximation, based on measurements in laminar acetylene/air diffusion flames [2].

\section{Soot Volume Fraction Distributions}

Time-averaged predictions of soot volume fractions are reported in the following, in order to be consistent with the measurements. Predictions are based on the soot volume fraction state relationships of Gore and Faeth [2].

Predicted and measured time-averaged soot volume fractions in the turbulent acetylene flames are plotted in Fig. 4 as a function of $r / x$ for various heights above the burner exit. Trends with respect to position and Reynolds number are predicted reasonably well in both the flaming and overfire regions of the flow, using the single soot volume fraction state relationship. Differences between predictions and measurements are generally comparable to experimental uncertainties and are certainly comparable to the anticipated performance of the predictions in view of the approximations of the turbulence model used to predict flame structure [10]. The greatest differences between predictions and measurements are observed at $x / d=53$, where predictions overestimate the width of the soot-containing region. Difficulties with the mixing analysis are probably the main cause of this problem; e.g., profile widths of all other scalar properties are somewhat overestimated at this position (see Figs. 1 and 2).

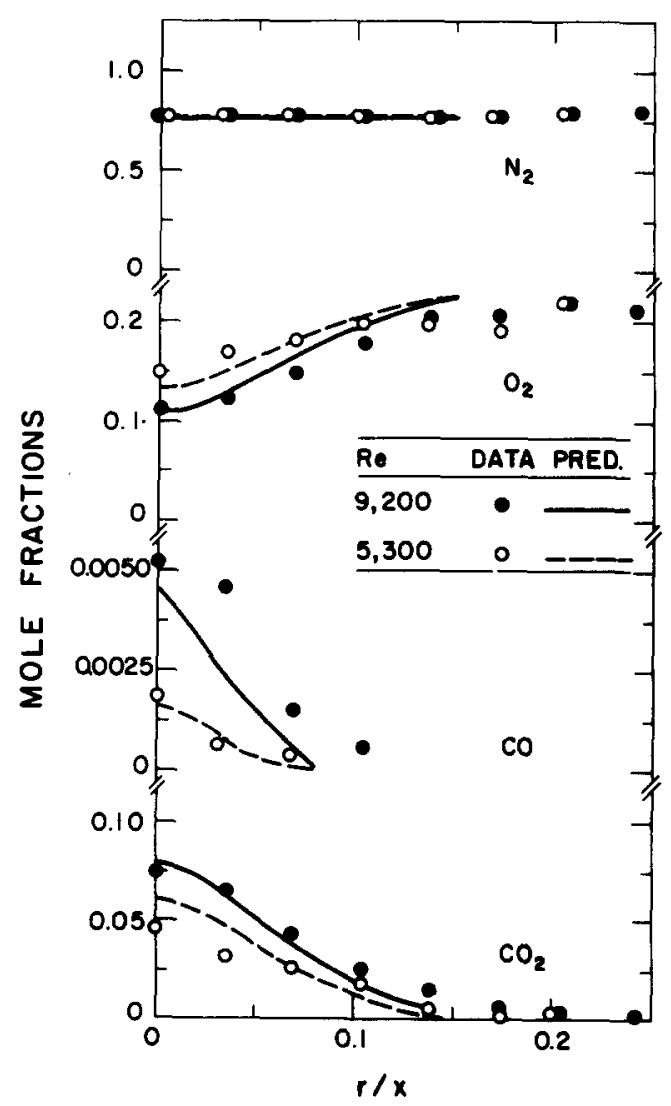

Fig. 3. Gas species concentrations (acetylene/air, $x / d=100$ ). 


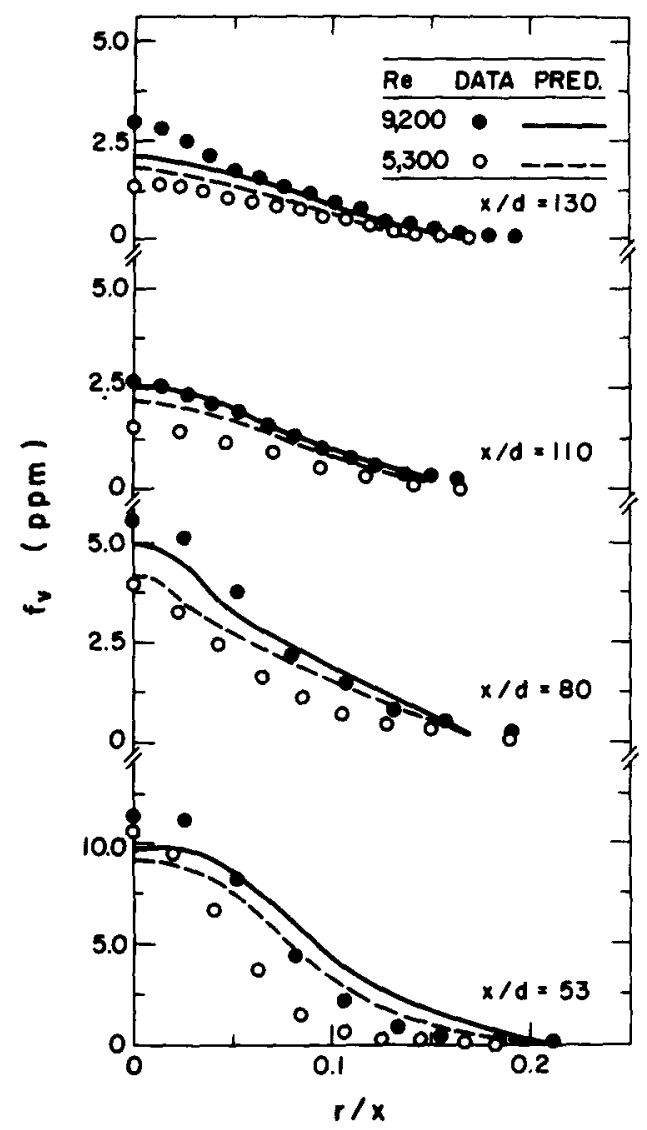

Fig. 4. Soot volume fraction distributions for acetylene/air.

\section{Correlation of Soot Volume and Mixture Fractions}

Predictions and measurements of soot volume fractions are cross-plotted directly as a function of mixture fraction (the soot volume fraction state relationship coordinates) in Fig. 5. The measurements are identified by flame Reynolds number and height above the source, but not by radial position, in order to reduce cluttering. The measurements represent time-averaged soot volume fractions as a function of mean mixture fractions as measured by the sampling system. As noted earlier, the mixture fraction measurements have indeterminant levels of density weighting but should fall between time and Favre averages, which are not very different for the conditions illustrated in Fig. 5. Experimental uncertainties, estimated as described earlier, are indicated by the crossed brackets located at both ends of the data range. The measurements are limited to overfire (lean) conditions, due to problems of measuring species concentrations in the flaming region, where soot concentrations are high.

Several correlations and predictions are also plotted in Fig. 5 including the lean portion of the soot volume fraction state relationship; found earlier [2], constructed for the limits of an adiabatic flame and a flame losing the measured radiative heat loss fraction. Differences between these limits are most significant near stoichiometric conditions, where the correlation allowing for radiative heat losses is probably most representative.

Relating time-averaged measurements in a turbulent flame to the instantaneous properties associated with a state relationship is questionable; therefore, potential effects of turbulent fluctuations have been illustrated in Fig. 5 by crossplotting predictions of time-averaged soot volume fractions and Favre-averaged mixture fractions in an attempt to simulate the measurements. These predictions were based on the standard soot volume fraction state relationships, allowing for radiative heat losses [2]. For acetylene, changes in burner Reynolds numbers and height above the burner exit had little effect on these plots; e.g., the two predictions illustrated in Fig. 5 bound all the results and are essentially identical. Effects of turbulent fluctuations are small for very lean conditions, where the time-averaged predictions for the turbulent flames merge with the state relationships. As stoichiometric conditions are approached, however, the turbulent predictions are biased above the soot volume fraction state relationship due to the presence of the soot spike on the fuel-rich side of the stoichiometric mixture fraction.

The soot volume and mixture fraction measurements illustrated in Fig. 5 appear to be correlated along single lines at each burner flow rate and height above the burner. This behavior, however, is an artifact of the measurements because all the soot volume fractions at a given flow rate and position are related to some extent through the deconvolution procedure. Otherwise, measurements at various burner flow rates and heights 


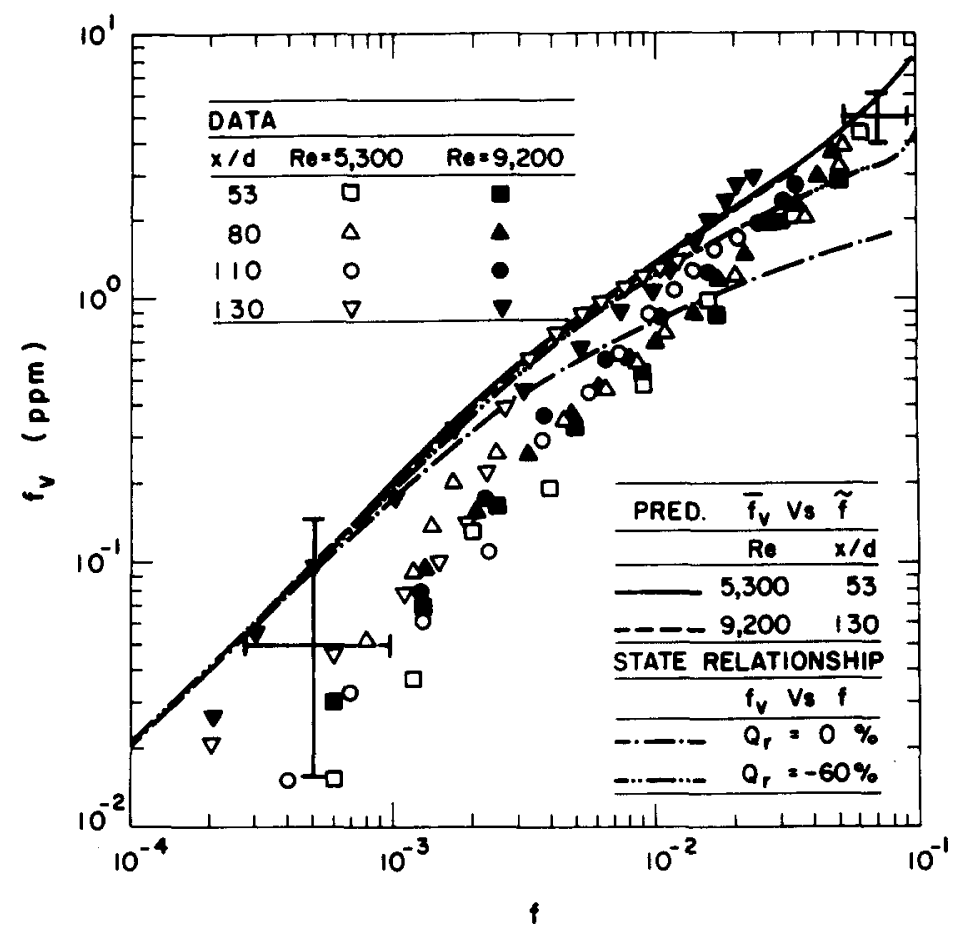

Fig. 5. Correlation between soot volume fraction and mixture fraction for acetylene/air. The stoichiometric mixture fraction is $\mathbf{0 . 0 7 0 2}$.

above the burner appear to be randomly distributed, with soot volume fractions and mixture fractions being correlated within experimental uncertainties. Present measurements are consistently below the state relationship of [2] at low mixture fractions, where effects of heat losses and turbulent fluctuations are small. However, the differences are within experimental uncertainties, so advocating an alternative correlation is questionable, particularly as the correlation of [2] performed reasonably well for predictions of soot volume fraction distributions illustrated in Fig. 4. As mixture fractions approach stoichiometric conditions, the present measurements tend to exceed the state relationships of [2], roughly following the predictions of effects of turbulent fluctuations in this region. Overall, the findings are supportive of the existence of nearly universal soot volume fraction state relationships, along the lines of [2], for the overfire regions of the present turbulent acetylene/air flames.

\section{Ethylene/Air Flames}

\section{Species Concentrations}

The properties just considered for the turbulent acetylene/air flames will now be examined for the turbulent ethylene/air flames. Predicted and measured mean mixture fractions are plotted in Fig. 6 as a function of $r / x$, for various heights above the burner exit. Flame tips are reached at $x / d \sim 85$ and 90 for the low and high Reynolds number flames. The comparison between predictions and measurements is not as good as the results for acetylene illustrated in Fig. 1, particularly for the higher Reynolds number ethylene flame, where predictions underestimate measured mixture fractions everywhere. The largest discrepancies between predictions and measurements are observed at the highest position, where room disturbances are probably a factor.

Typical predictions and measurements of the molar fractions of major gas species are plotted in 


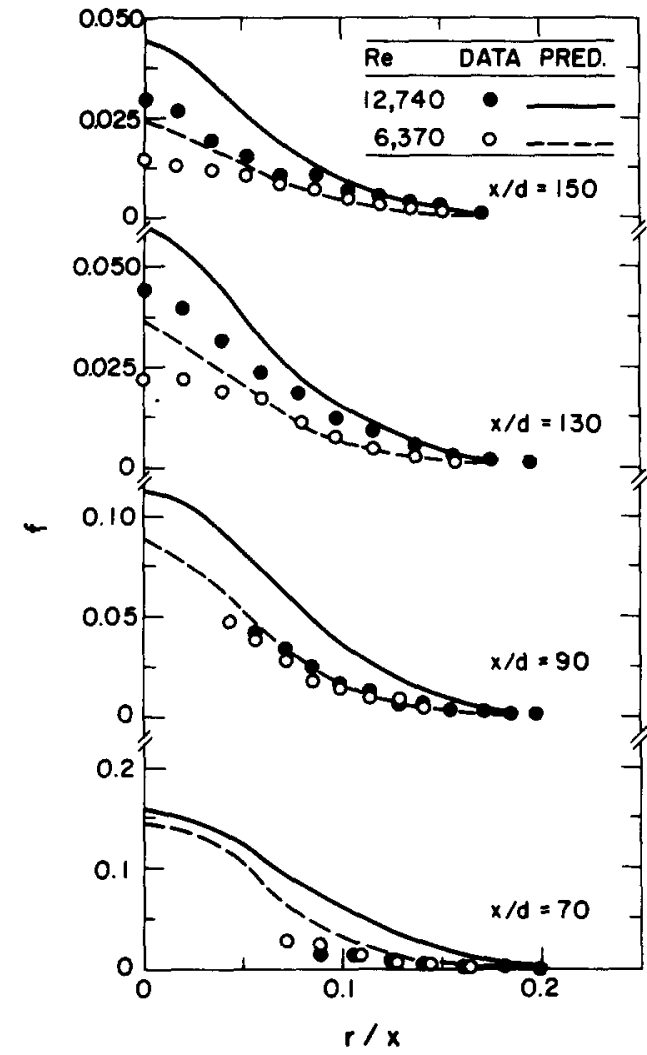

Fig. 6. Mixture fraction distributions for ethylene/air.

Figs. 7 and 8 as a function of $r / x$, for $x / d=50$ and 90 . The comparison between predictions and measurements is similar to the findings for acetylene, with somewhat increased deficiencies being attributable to the poorer predictions of mixing for ethylene, e.g., poorer predictions of mixture fraction distributions in the flames. In view of the approximations of the turbulent mixing analysis, and experimental uncertainties, the state relationships for gas species of [1] appear to be acceptable for the overfire region of the present turbulent ethylene/air flames.

\section{Soot Volume Fraction Distributions}

Time-averaged predictions and measurements of mean soot volume fractions are illustrated in Fig. 9 as a function of $r / x$ for various heights above the burner exit. Trends with respect to position and Reynolds number are represented reasonably well by a single soot volume fraction state relationship.
However, quantitative agreement between predictions and measurements is poorer than for the acetylene/air flames illustrated in Fig. 4. Because ethylene soot volume fractions are roughly an order of magnitude smaller than those of acetylene, generally higher experimental uncertainties are probably involved in this observation. Room disturbances, coupled with rather large experimental uncertainties, are mainly responsible for the poorer agreement between measurements and predictions at the highest position illustrated in Fig. 9.

\section{Correlation of Soot Volume and Mixture Fractions}

Measurements and predictions of soot volume fractions and mixture fractions for the ethylene

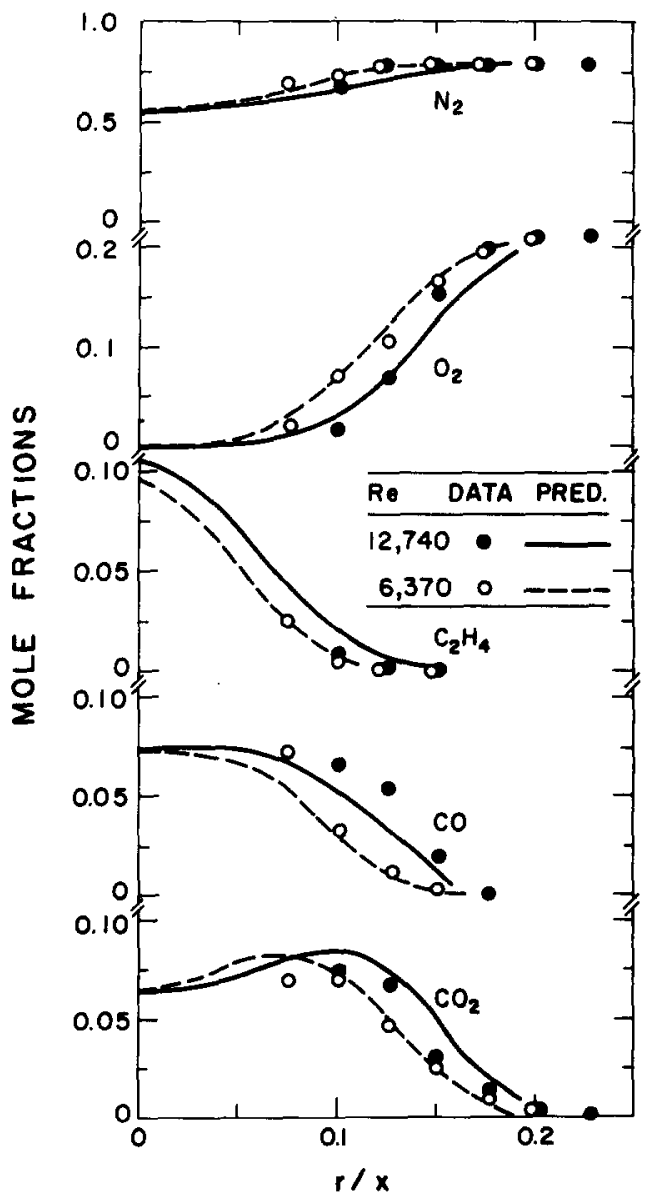

Fig. 7. Gas species concentrations (ethylene/air, $x / d=50$ ). 


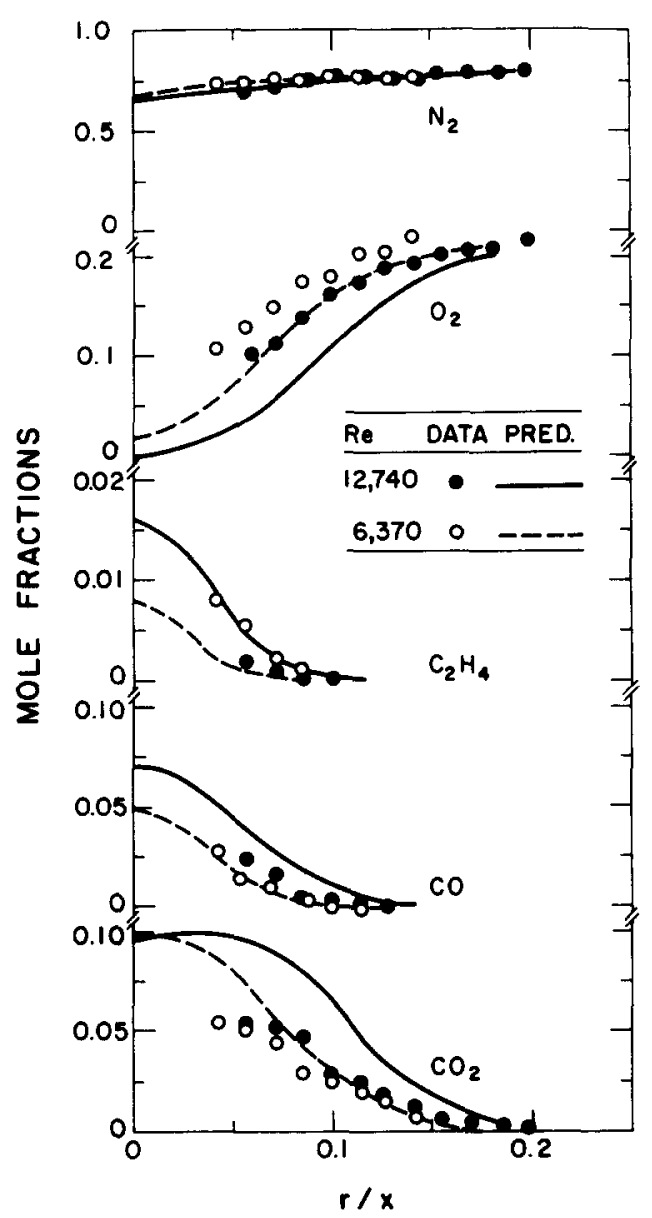

Fig. 8. Gas species concentrations (ethylene/air, $x / d=90$ ).

flames are cross-plotted in Fig. 10, similar to the acetylene/air results pictured in Fig. 5. The near stoichiometric conditions of the predictions indicate greater biasing of observed time-averaged soot volume fractions above the state relationship and greater effects of flame Reynolds number and height above the burner on the degree of biasing, due to turbulence, than was observed for acetylene (see Fig. 5). This behavior is observed because maximum soot concentrations in the soot spike are much higher than soot concentrations in the lean region, and the spike is closer to the stoichiometric mixture fraction for ethylene than for acetylene [ 1 , 2].

Measurements for the lower Reynolds number flame (Fig. 10, open symbols) are similar to the findings for acetylene. The results fall along the soot volume fraction state relationships at low mixture fractions, where effects of turbulent fluctuations and local variations in radiative heat loss fractions are small. As the mixture fraction increases toward the stoichiometric mixture fraction, the measurements are biased upward from the state relationships, similar to the turbulence predictions. Disregarding the apparent correlation of the measurements at each height above the burner, as this is probably caused by their determination from a single deconvolution, these measurements are randomly distributed. For low mixture fractions, the measurements agree with the state relationships well within experimental uncertainties. For high mixture fractions, data scatter is somewhat greater than experimental uncertainties, but this behavior is expected based on the results of the turbulent predictions because of the effect of height above the burner exit on the

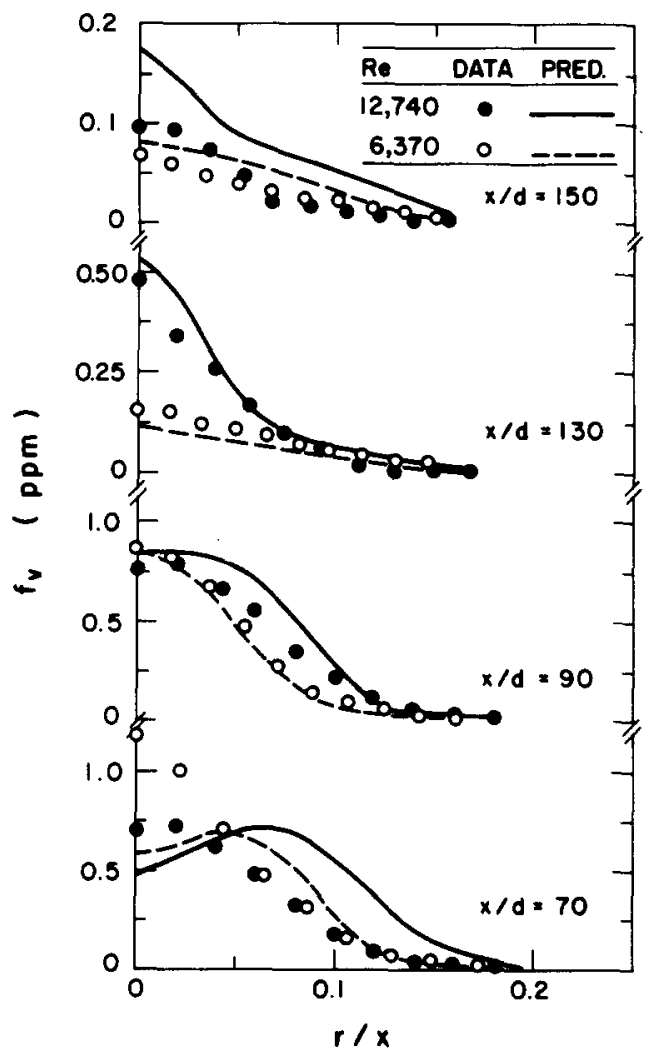

Fig. 9. Soot volume fraction distributions for ethylene/air. 


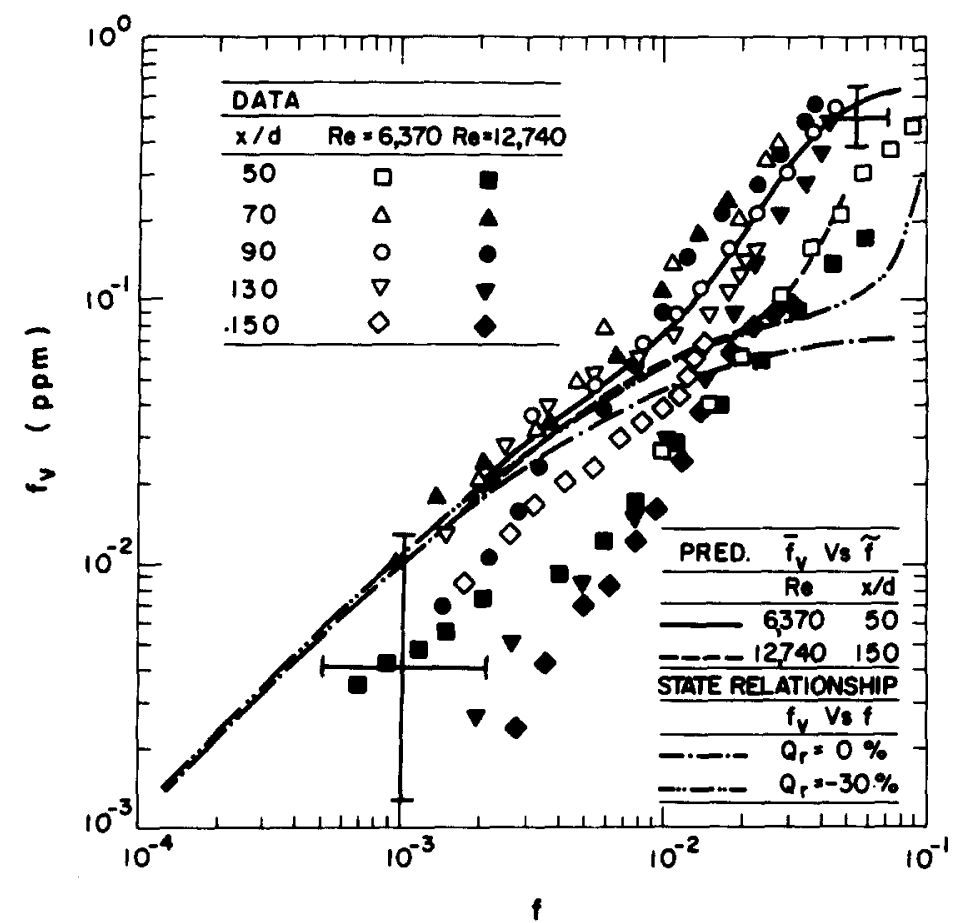

Fig. 10. Correlation between soot volume fraction and mixture fraction for ethylene/air. The stoichiometric mixture fraction is 0.0634 .

degree of biasing of the time-averaged soot volume fractions. Thus, results for the low Reynolds number ethylene flame are generally supportive of a universal soot volume fraction state relationship in the overfire region.

In contrast, results for the high Reynolds number ethylene flame, illustrated in Fig. 10, exhibit much greater scatter. This is particularly true for low mixture fractions, where scatter of the measurements exceeds the rather large range of estimated experimental uncertainties shown on the figure, even though effects of radiative heat losses and turbulent fluctuations are small. This behavior could be an indication of failure of the laminar flamelet concept for soot volume fractions due to effects of finite-rate chemistry. The high Reynolds number flame for ethylene has the shortest characteristic residence time of all the flames considered, while the findings of Becker and Liang [14] suggest significantly longer characteristic chemical times needed to reach the plateau region of soot generation efficiencies for ethylene than for acety- lene. Because characteristic residence times vary for different paths through the flame, this would imply different soot volume fractions when soot oxidation is quenched, and different correlations of soot volume fractions as a function of mixture fraction during subsequent passive mixing of soot in the overfire region. Thus, the results illustrated in Fig. 10 suggest potential for universal soot volume fraction state relationships for ethylene, but only at sufficiently large characteristic flame residence times. Additional measurements for a wider range of conditions, with better control of experimental uncertainties, will be needed for an adequate evaluation of the laminar flamelet concept for soot volume fractions, and the range of conditions where this applies must be determined.

\section{Soot Generation Efficiencies}

Soot generation efficiencies were computed for the overfire region of the test flames. The density of soot for these calculations was taken to be 1100 
TABLE 2

Soot Generation Efficiencies ${ }^{a}$

\begin{tabular}{llc}
\hline & \multicolumn{2}{c}{ Fuel } \\
\cline { 2 - 3 } \multicolumn{1}{c}{ Source } & Ethylene & Acetylene \\
\hline $\begin{array}{l}\text { Present study } \\
\text { all flames }\end{array}$ & $0.010(0.006)$ & $0.11(0.07)$ \\
$\begin{array}{l}\text { low Reynolds number } \\
\text { ethylene flame }\end{array}$ & $0.012(0.006)$ & - \\
$\begin{array}{l}\text { Gore and Faeth [1, 2] } \\
\text { Newman and Steciak [15] } \\
\text { Becker and Liang [14] }\end{array}$ & 0.012 & 0.21 \\
\hline
\end{tabular}

${ }^{a}$ For diffusion flames in still air with reactants initially at normal temperature and pressure.

${ }^{b}$ Estimated from soot volume fraction measurements using a soot density of $1100 \mathrm{~kg} / \mathrm{m}^{3}$, from Newman and Steciak [15].

c Numbers in parentheses denote standard deviations.

${ }^{d}$ For characteristic residence times (as defined in Ref. [14]) greater than $180 \mathrm{~s}$ for ethylene and $70 \mathrm{~s}$ for acetylene.

$\mathrm{kg} / \mathrm{m}^{3}$, which is the value recently found by Newman and Steciak [15] for a variety of hydrocarbon fuels (including ethylene) in the overfire region of buoyant diffusion flames. Only those results for which analysis showed that effects of biasing due to turbulent fluctuations were relatively small were used ( $f<0.02$ for acetylene and $f<0.01$ ethylene, see Figs. 5 and 10). The results are summarized in Table 2 . Because effects of finite-rate chemistry are suspected for the high Reynolds number ethylene flame, separate values are given using 1) data from both flames, and 2) only data from the low Reynolds number flame. In addition to present measurements, other results summarized in Table 2 include: soot generation efficiencies inferred from the state relationships of $[1,2]$, a value for ethylene reported by Newman and Steciak [15], and values for both fuels obtained from the measurements of Becker and Liang [14]. Flame conditions for the Newman and Steciak [15] result were not prescribed. The measurements from Becker and Liang [14] are for the plateau region at longer characteristic residence times, where soot generation efficiencies were relatively independent of burner operating conditions. Becker and Liang [14] found soot concentrations by sampling, while soot concentrations were found from extinction measurements for the other results summarized in Table 2 .

Present measurements generally agree, within 1SD, with the other values listed in Table 2 . As suggested by the results illustrated in Figs. 5 and 10 , present soot generation efficiencies-considering all the flames-are somewhat lower than the values found by Gore and Faeth [1, 2], while considering only the low Reynolds number ethylene flame yields values just slightly higher than those of [1]. Soot generation efficiencies from the present study and [1] are $30-40 \%$ lower than the value reported by Newman and Steciak [15] for ethylene. Aside from potential differences due to different flame conditions, interpretation of the extinction measurements could be responsible for this discrepancy. Newman and Steciak [15] used Mie scattering theory and refractive indices for soot from Tien and Lee [3], while present results are for the Rayleigh scattering approximation using refractive indices from Dalzell and Sarofim [20]. The effect of the Rayleigh scattering approximation is difficult to evaluate without information on soot particle size distributions [12]; however, calculations of Santoro et al. [22] suggest 5-15\% reductions of present estimates of soot generation efficiencies if Mie scattering theory is used. In contrast, use of the refractive indices of Tien and Lee [3] would increase present estimates of soot volume fractions by $30-40 \%$. In view of these considerations, the soot generation efficiency for ethylene reported by Newman and Steciak [15] is reasonably consistent with the results from this laboratory. The sampling measurements of Becker and Liang [14] are smaller than the optical measurements, particularly for ethylene, perhaps because of incomplete collection of soot (a frequent problem with sampling methods) or effects of additional uncertainties in soot densities.

The values of the overfire soot generation efficiency for acetylene are quite high, comparable to PVC and polystyrene [15]. If the overfire soot density is still appropriate for fuel-rich conditions, the earlier laminar flame measurements [2] suggest soot generation efficiencies on the order of $100 \%$ at the peak of the soot spike in the fuel-rich region. This value seems high and could be 
influenced by the effects of differential diffusion. ${ }^{3}$ This near-saturation behavior, however, could explain why maximum soot volume fractions in laminar acetylene/air diffusion flames were relatively independent of height above the burner exit in spite of shifts in the mixture fraction where the peak was observed [2].

Present findings, and the results of others summarized in Table 2, suggest that soot generation efficiencies of the luminous diffusion flames as a whole-and point-to-point within the overfire region-may be roughly constant when characteristic residence times are sufficiently large, i.e., in the plateau region observed by Becker and Liang [14]. This implies at least roughly universal soot volume fraction state relationships for the overfire region, which would be a very helpful property for radiation computations on luminous turbulent diffusion flames. In order to adequately assess the potential of this simplification, additional data, with reduced experimental uncertainties, are needed for a wider range of fuels, flame configurations, and operating conditions.

\section{CONCLUSIONS}

Scalar properties in the overfire (lean) region of turbulent ethylene and acetylene diffusion flames burning in air were considered both theoretically and experimentally. The major conclusions of the study are as follows:

1. Mean concentrations of major gas species and mixture fractions were predicted reasonably well, similar to past experience, with the present analysis for round turbulent diffusion flames $[1,2,8-11]$.

2. Consideration of both laminar and turbulent flames suggests nearly universal state relationships for major gas species, which closely approximate local thermodynamic equilibrium, in the overfire region of turbulent sooting acetylene and ethylene diffusion flames.

3. Predictions of time-averaged soot volume frac-

\footnotetext{
${ }^{3}$ Mass diffusivities of soot particles are small in comparison to gases, which would tend to trap excess fuel carbon in the soot layer.
}

tion distributions in the turbulent flames, using soot volume fraction state relationships found earlier $[1,2]$, were reasonably good in view of experimental uncertainties and the approximations of the analysis to find flame structure.

4. Direct evaluation of soot volume fraction state relationships for the overfire region was hampered by effects of turbulent fluctuations (near stoichiometric conditions) and large experimental uncertainties (for very lean conditions). Within these limitations, present findings support nearly constant soot generation efficiencies from point to point in the overfire region at sufficiently large characteristic residence times, and yield soot volume fraction state relationships similar to earlier proposals $[1,2]$. However, effects of finite-rate chemistry were noted at shorter residence times for ethylene, causing spatial variations of soot generation efficiencies (and thus the soot volume fraction state relationships) in the overfire region.

5. Present measurements of soot generation efficiencies for flames having long characteristic residence times were in fair agreement with earlier measurements based on optical methods-once effects of Mie scattering corrections and different correlations for soot refractive indices were considered $[1,2,15]$-and with sampling measurements reported by Becker and Liang [14].

These findings suggest that soot volume fraction state relationships are potentially a useful concept that can help to circumvent the complexities of soot chemistry in turbulent flames in some instances, at least for the purpose of estimating soot properties for radiation predictions. This concept also provides a useful perspective from which to consider effects of finite-rate chemistry and transport on soot processes in turbulent flames. Further evaluation of this concept for a wider range of fuels and flame conditions appears to be warranted.

This research was supported by the Center for Fire Research of the National Bureau of Standards, Grant No. 60NANB5D0576, with Dr. B. J. McCaffrey serving as NBS Scientific 
Officer. The authors would also like to acknowledge valuable suggestions by the reviewers.

\section{REFERENCES}

1. Gore, J. P., and Faeth, G. M., Twenty-First Symposium (International) on Combustion, The Combustion Institute, Pittsburgh, pp. 1521-1531, 1986.

2. Gore, J. P., and Faeth, G. M., J. Heat Trans. 110:173181 (1988).

3. Tien, C. L., and Lee, S. C., Prog. Energy Combust. Sci. 8:41-59 (1982).

4. Bilger, R. W., Comb. Flame 30:277-284 (1977).

5. Liew, S. K., Bray, K. N. C., and Moss, J. B., Comb. Sci. and Tech. 27:69-73 (1981).

6. Liew, S. K., Bray, K. N. C., and Moss, J. B., Comb. Flame 56:199-213 (1984).

7. Faeth, G. M., and Samuelsen, G. S., Prog. Energy Combust. Sci. 12:305-372 (1986).

8. Gore, J. P., Jeng, S.-M., and Faeth, G. M., J. Heat Trans. 109:165-171 (1987).

9. Gore, J. P., Jeng, S.-M., and Faeth, G. M., AIAA J. 25:339-345 (1987).

10. Jeng, S.-M., and Faeth, G. M., J. Heat Trans. 106:721-727 (1984).

11. Jeng, S.-M., and Faeth, G. M., J. Heat Trans. 106:891-893 (1984).
12. Kent, J. H., and Bastin, S. J., Comb. Flame 56:29-42 (1984).

13. Kent, J. H., Comb. Flame 67:223-233 (1987).

14. Becker, H. A., and Liang, D., Comb. Flame 44:305318 (1982); Ibid, 52:247-256 (1983).

15. Newman, J. S., and Steciak, J., Comb. Flame 67:55-64 (1987).

16. Santoro, R. J., Semerjian, H. B., and Dobbins, R. A., Comb. Flame 51:203-218 (1983).

17. Pagni, P. J., and Okoh, C. I., Twentieth Symposium (International) on Combustion, The Combustion Institute, Pittsburgh, pp. 1045-1054, 1985.

18. deRis, J., Seventeenth Symposium (International) on Combustion, The Combustion Institute, Pittsburgh, pp. 1003-1016, 1979.

19. Gore, J. P., "A Theoretical and Experimental Study of Turbulent Flame Radiation," Ph.D. Thesis, The Pennsylvania State University, University Park, PA, 1986.

20. Dalzell, W. H., and Sarofim, A. F., J. Heat Trans. 91:100-104 (1969).

21. Bilger, R. W., Prog. Energy Combust. Sci. 1:87-109 (1976).

22. Santoro, R. J., Dobbins, R. A. and Semerjian, H. G., Progress in Astronautics and Aeronautics 92:343-382 (1984).

Received 9 March 1987; revised 16 December 1987 